\title{
Cómo el periodismo hace cultura en el proceso por develar un modelo cultural en las llamadas revistas culturales*
}

\author{
How journalism makes culture in the process \\ of unveiling a cultural model in magazines \\ designated as cultural
}

JAIRO ENRIQUE VALDERRAMA VALDERRAMA**

jairo.valderrama@unisabana.edu.co

Recepción: 19 de octubre de 2012

Aprobación: 22 de enero de 2013

\footnotetext{
* Este artículo se deriva de un detallado rastreo acerca de las investigaciones que plantean o aluden al papel que cumple el periodismo en la construcción o deconstrucción cultural, y es uno de los apartados de la tesis doctoral del autor. La investigación general se centra en develar un modelo cultural en un periodo determinado de la revista Magazín Dominical que circuló en versión impresa con el diario El Espectador de Bogotá, Colombia.

*** Doctorando en Ciencias de la Comunicación de la Universidad Austral de Buenos Aires, Argentina. Comunicador social y periodista, docente e investigador de la Universidad de la Sabana, en Colombia. Miembro del Grupo de Investigación en Periodismo, GIP, de la Facultad de Comunicación, y del grupo Valor y Palabra, de la Facultad de Filosofía y Ciencias Humanas, ambos de la Universidad de la Sabana, Colombia.
} 


\section{Resumen}

Con base en una investigación cuyo objetivo central consiste en develar algún modelo de cultura de las revistas designadas como tales, se expone aquí un rastreo acerca de cómo el periodismo enriquece, altera, preserva o disminuye las características y manifestaciones propias de un grupo humano, independientemente de si la actividad informativa trata acerca de esos mismos asuntos. La información económica, política, deportiva, científica, etc. también va revestida de cultura, y en ésta parecen importar más la verosimilitud que la realidad misma, la posibilidad de creer en una versión antes que en la verdad de ésta y, sobre todo, en manejar el llamado entretenimiento, que funciona como fortísima cortina de humo.

La mayor parte de los motivos para ejercer un control recurrente de los contenidos masificados se ha centrado, primero, en la escritura oficial; luego, en las ideas propagadas que generó la invención de la imprenta; más tarde, en los medios impresos y, en el último siglo, en los medios electrónicos de comunicación.

Palabras clave: revistas culturales, cultura, periodismo.

\section{Abstract}

Based on a research study whose main objective consists in unveiling a model of culture in magazines designated as cultural, this article presents an exploration of how journalism enriches, alters, preserves or diminishes the characteristics and manifestations of a human group, regardless of whether the informative activity is about those same matters. Economic, political, sports, scientific, and other information is also enmeshed in culture, a conception of culture where verisimilitude seems to matter more than reality itself, with the possibility of believing in a version more than the truth expressed on it, and above all the manipulation of so called entertainment which works as a fortified smoke screen.

Most of the reasons to implement a recurrent control of the massified contents have focused first on official writing, then in the propagation of ideas that created to the invention of the printing press, Later in printed media, and in the last century in the electronic media.

Key words: cultural magazines, culture, journalism. 


\section{Introducción}

En el siglo XVIII, la escritura y la lectura son privilegios de los letrados, y la relación entre los escritos y la sociedad sólo deja que los primeros se impongan y encuadren en la segunda "dentro de un molde no hecho a su medida" (Rama, 1985). Pero, desde más atrás, al establecerse las primeras civilizaciones, los mensajes públicos, casi todos provenientes de los gobiernos, trazan los modelos o los paradigmas que motivan a bosquejar las culturas y, con ellas, las estructuras sociales.

Quizás la más recurrente y la única ${ }^{1}$ que cumple el papel de medio masivo, la escritura oficial propaga las ideas y, por tanto, los procederes que han de adoptar casi todos los pueblos, al menos en Occidente. Esa actividad, a manera de periodismo, instaura los referentes de vida, del pensar y del hacer... de la cultura.

Con la imprenta, en el siglo XV, se adquieren las libertades públicas de expresión y difusión de ideas; se incrementa el índice de alfabetización; con la escritura se forma opinión y se culturiza. Todo ello, a pesar de los esfuerzos del poder por controlar los contenidos y la circulación de los primeros impresos (Rodríguez, 2006). La evolución de los medios de comunicación, así, se acelera. En ese proceso, las orientaciones en modos de pensar y actuar de pueblos enteros toman gran cantidad de las ideas publicadas.

Acotar algunas de las investigaciones en esta materia permite considerar cómo muchos modos de generar efectos masificados se conservan, y otros han cambiado. También se posibilita una visión, así sea somera, de la investigación en el campo de la comunicación masiva para abrir un

\footnotetext{
También, a viva voz, el discurso de los hombres públicos cumplía un papel semejante al trasmitir las determinaciones del poder a los súbditos, al pueblo. Sin embargo, con los mismos contenidos de la expresión escrita, el lenguaje oral permitía ampliar el número de receptores, casi todos analfabetos. La escritura se consolidó "como un método de comunicación efectivo que adquirió, en sociedades evolucionadas como la romana, una importancia fundamental para el funcionamiento social, si bien la comunicación oral fue hegemónica durante muchos siglos para una población que no llegó a la alfabetización mayoritaria sino en los albores del siglo XX". (Rodríguez, 2006).
} 
sendero y exponer algunos de los esfuerzos para develar las características de los grupos humanos y su relación directa con los medios masivos, de los cuales reciben información.

Por ahora, se posterga la definición de periodismo cultural, como se conoce de manera genérica en casi todos los ámbitos de la comunicación masiva. Se trata, en un primer paso, de bosquejar la influencia o el efecto del periodismo sobre la cultura.

\section{Algunos estudios}

La relación entre periodismo y cultura, apenas en los años ochenta, empieza a conformarse con las llamadas "comunidades académicas" en Latinoamérica, en México, Brasil, Venezuela y Chile, integradas desde 1978 en la Asociación Latinoamericana de Investigadores de Comunicación, ALAIC (Barbero y Rey, 1999).

Son diferentes los estudios de mercado y de investigación crítica $^{2}$, con el examen integral y todas las posibilidades de esta última designación. Sin embargo, esos primeros intentos corroboran los recursos del dominio político, que toma como instrumentos a los medios masivos. Aún es necesario determinar, por ejemplo, cómo la comunicación constituye parte integral de la cultura, y cómo, en un efecto continuo, aparecen los cambios de la dinámica social. Sin embargo, la semiótica, el análisis de discurso, la lingüística, las descripciones y el estudio de los contenidos, entre otros frentes, desentrañan objetos comunicativos que antes pasaban desapercibidos (Barbero y Rey, 1999).

Sobre los objetos propios de la comunicación, también allí se han adelantado los investigadores de la antropología, la sociología, la psicología o la ciencia política (Barbero y Rey, 1999). Según Jesús Martín Barbero y Germán Rey (2006), en Colombia particularmente, el Cinep ${ }^{3}$ se constituye en el instituto pionero de "investigaciones sobre los modos populares

\footnotetext{
2 Se ha de tomar la acepción de crítica aquí, en esta investigación, como el recurso más adecuado para examinar, con visión y criterio amplio, un fenómeno social y, sobre todo, una manifestación artística particular. Esta última es también una manera distinta pero válida de interpretar la realidad; todo depende de si se toma en su integridad. En los dos casos, como estudio de un caso social o de una obra artística específica, los referentes para garantizar una mirada amplia son estos tres: el fenómeno social mismo (o la obra, o el objeto de estudio, según el caso), la teoría que al respecto se ha trazado (o los antecedentes, en el caso de la obra) y en el marco histórico (las circunstancias de época y lugar) (Barcia, 1999).

3 "El Centro de Investigación y Educación Popular/ Programa por la Paz (CINEP/PPP) es una fundación sin ánimo de lucro que anima el cambio social desde las orientaciones de la Compañía de Jesús en Colombia. Trabaja por la edificación de una sociedad más justa, democrática y en paz desde una opción preferencial por hombres y mujeres que han sido excluidos y las víctimas. Para ello, genera alternativas para la construcción de la paz, el desarrollo humano integral, la realización de los derechos yla ampliación de la democracia, desde la investigación y producción de información, la educación, el acompañamiento a procesos sociales, el ejercicio de la incidencia y la comunicación". En ¿Quiénes somos?: http://www.cinep.org.co/29/11/2011.
} 
de comunicación y de relación con los medios". Se requiere un investigador (en sentido genérico) que interprete esos modos de ver de la cultura popular.

Junto a esta iniciativa, la Universidad del Valle ${ }^{4}$ intenta allanar las relaciones entre culturas popular y masiva (Barbero y Rey, 1999). Y en Colombia, por lo menos se descubre que la cantidad de tiempo frente a los medios no influencia tanto como las imágenes que construye la audiencia en los procesos de percepción:

[...] hondas transformaciones en la cultura cotidiana de las mayorías, esto es, en sus modos de juntarse y de tejer lazos sociales, en las identidades que plasman esos cambios y en los discursos en que emergen socialmente. Investigar la comunicación se convierte así en la indagación de: -las transformaciones que atraviesa la identidad nacional desubicada tanto por el movimiento de homogenización que produce la cultura-mundo como por la revaloración de las culturas regionales y locales que los propios medios potencian; - el nuevo sentido que adquieren las culturas tradicionales sometidas a intensos procesos de interacción e hibridación que la multiplicación de las comunicaciones producen hasta en las regiones más apartadas (Barbero y Rey, 1999).

En general, Barbero y Rey (2006) exponen nuevos enfoques en comunicación. Recalcan, en las perspectivas culturales: cultura tecnológica, mundo audiovisual, medios como escenarios de conflicto, cambios en la representación política, nuevos actores sociales (étnico, barrial, ecológico, etc.) y retos de la comunicación en la educación.

Catalina González coincide en la relación cultura-comunicación: "cualquier esfuerzo por comprender un aspecto de nuestra cultura es una colaboración al horizonte utópico del entendimiento social que se perfila como esperanza para la difícil sociedad de nuestro espacio y tiempo" (1993).

En España, la cantidad de investigaciones sobre cultura y medios es amplia. Amparo Tuñón (1990), periodista y profesora de periodismo de la Universidad Autónoma de Barcelona, por ejemplo, ha centrado sus indagaciones en el análisis del discurso cultural periodístico de los diarios.

Tuñón (1990) dice que los medios de comunicación se han constituido en una cultura hegemónica, porque conforman creencias y valores, como la religión o el arte; además, los medios inciden en los modos de vida.

\footnotetext{
4 Universidad pública situada en la ciudad de Cali, departamento del Valle, en el occidente de Colombia. (N. del A.).
} 
[...] Los medios conforman símbolos, imágenes, valores, pautas de comportamiento y estilos de vida significativos. En última instancia, modelan una cultura propia ya que aportan una visión del mundo y una forma específica de conocimiento sobre la realidad actual. Realidad que, por otra parte, ellos mismos ayudan a configurar. (Tuñón, 1990, p. 28).

La fuerza del discurso de los medios (sobre todo de la prensa) se nota más porque éste se muestra como el representante del discurso generalizado; "es el legitimador del discurso público" (1990); conlleva las versiones de los hechos que se admiten como verdad, sin que lo sean necesariamente. De ahí el poder que entrañan. En estos diarios ${ }^{5}$, la información cultural aborda por lo regular temas alusivos la cultura clásica: artes, letras, cine, música, añadiendo el estilo, el diseño o la fotografía. (Tuñón, 1990).

Los ideales de esa prensa aún están soportados en el modernismo, el progreso, la libertad; y en los principios tomados de la Ilustración: verdad, razón y objetividad (Tuñón, 1990). Estas perspectivas de la información resultan distintas en otro tipo de prensa: la sensacionalista o la llamada tecno-informativa. En la primera, la "cultura" está en los chismes, la vida privada o el escándalo; para la segunda, en la salud y el entretenimiento.

No obstante, de nuevo, las noticias de cultura en esta prensa de élite ${ }^{6}$ son los hechos previstos, prefabricados, ya institucionalizados, como si esas manifestaciones culturales se expidieran por decreto ${ }^{7}$. Allí caben las exposiciones, congresos, premios menores, inauguraciones, estrenos, coloquios, presentaciones de libros.

Más que el registro simple de los hechos, el diario El País, de España, como referente de la fuerza constructora de cultura, se dedica a construir "realidades", a insistir en modelos que dejan de serlo para incorporarse a los imaginarios de los lectores y a ser asumidos como

5 Amparo Tuñón alude, por supuesto, al diario El País de Madrid, al que califica de prensa élite o prensa de referencia, para indicar que ésta marca la pauta generalizada en los reducidos grupos de intelectuales, reducidos si se comparan con el número total de lectores (N. del A.). El diario El País establece tres categorías para tratar la cultura, según Tuñón: cultura/noticia, cultura/acontecimiento y cultura/conocimiento (1990).

6 En la sección que se examina en el diario El País aparece en la parte superior el cabezote: "La Cultura", con una carga semántica que estrecha la definición de cultura y la restringe sólo a los campos abarcables por las letras, el teatro, la ópera y las artes plásticas; es decir, otra vez la acepción de cultura para la "prensa de élite". La carga del artículo "la" antes de la palabra "cultura" en ese cabezote también refuerza la exclusión de otras visiones sobre tal concepto.

7 "Para que un estado haga algo más que administrar privilegios y defenderse de su propia población, sus actos deben estar de conformidad con los de aquellos que según él pretende son sus ciudadanos y, en un sentido amplificado, deben ser actos de sus ciudadanos. Aquí no se trata de una mera cuestión de consenso. Un hombre no tiene por qué estar de acuerdo con los actos de su gobierno para considerarse identificado con ellos, así como no tiene por qué aprobar sus propios actos para reconocer que fue él mismo quien los realizó. (Geertz, 2005). 
"verdades". Los teóricos de la comunicación fluctúan entre afirmar que los medios inciden en la conformación de la cultura, en la eliminación de algunas de sus características, o que generan cambios en ésta.

El aporte ${ }^{8}$ de Tuñón consiste en probar que los medios preservan la cultura, la refuerzan 0 la crean, y para ello, entre otros recursos, están los mitos:

Sin embargo, el diario El País construye un mito sobre una realidad más imaginaria que real y una verdad más verosímil que verdadera [... L La muerte por cornada es, sin embargo, un legado de hondas raíces mitológicas en la cultura española y por lo tanto de fácil identificación con el lector. La muerte por cornada es asimismo un estereotipo cultural legado por los medios y anteriormente por el sentir y el sentido común. (Tuñón, 1990, p. 39).

El periodismo y la cultura, desde un enfoque distinto, indican también cómo los medios avivan la industria cultural. Una vez más, los fenómenos culturales, su dinamismo interno y el cambio de los modos de vida de cada pueblo no son espontáneos. Al parecer, hay un carril invisible para encauzar las apreciaciones de la realidad de los receptores.

\section{Cultura y culturas}

La investigadora Moraima Guanipa, de la Universidad Central de Venezuela, propone examinar el periodismo cultural', no tanto desde el trabajo informativo y especializado donde generalmente ha estado - como se aclaró al inicio de este apartado-, sino tomando consideraciones más duraderas y de mayor hondura.

Así, Guanipa (2010) se centra en los procesos masivos comunicacionales de carácter masivoindustrial y la conformación de mapas culturales de la sociedad contemporánea, propios de su línea de investigación. En las lecturas constantes, para "desentrañar lo habitual de lo inusual y lo ordinario de lo extraordinario", Said, 2006, citado por Guanipa (2006, p. 9), expone las amplias posibilidades del estudio de la cultura y la comunicación:

De allí que podríamos hablar de comunicación e información cultural como un eje de interés que a lo largo del tiempo se ha diversificado en derivaciones temáticas más concretas: información cultural; comunicación y cultura; cibercultura, así como crítica de arte, prensa y canon.

\footnotetext{
8 El despliegue informativo del diario El País sobre la muerte del torero Paquirri en España.

9 El tema puntual de periodismo cultural se tratará en el siguiente numeral (N. del A.).
} 
Las posturas diversas acerca de los medios masivos y cultura, y cómo éstos moldean a aquella, provienen de diversos frentes. En Argentina, también se han extendido corrientes distintas en los estudios culturales frente a la llamada posmodernidad. (Follari, 2000).

En ese propósito, hay defensas y ataques, puntos de vista parcialmente admitidos y otros plenamente rechazados. Roberto Follari (2000), profesor titular de Epistemología de la Universidad Nacional de Cuyo, defiende a Néstor García Canclini cuando "una autora" lo califica de positivista; en otro caso, ese mismo autor señala cómo Beatriz Sarlo, la autora, debería de permitir un diálogo "razonable" ante el rechazo contundente frente al papel de la televisión, al menos en Argentina.

El mismo Follari (2000) califica de "lamentables" los contenidos de la televisión y, por supuesto, el efecto de ésta en la cultura; pero da también posibilidad a que Beatriz Sarlo considere que la cultura no puede entenderse sólo desde el plano meramente estético. "Esto implica sin duda un elitismo cultural desde el cual se interpreta, como desde un pedestal, a la cultura visual como cultura de la decadencia". La televisión roba tiempo para la lectura, para la reflexión, obliga al consumismo; pero también -argumenta Follariahora existe cercanía a la información, apertura al universo de los mensajes, discusión política visible, percepción del rostro de los emisores, etc. Una conclusión en estas relaciones de posmodernidad y cultura da una visión concisa de Follari: "Lo posmoderno no se entiende sin los estudios culturales ni se entiende solamente con ellos" (2000).

De manera semejante, se diría que el papel del periodismo en la cultura resultaría confuso sin las distinciones entre las tareas propias de un periodista frente a las de un antropólogo. Los periodistas trabajan a contrarreloj, cubren zonas extensas, estudian casos diversos, disponen de tiempo corto y espacio reducido... su público es amplio. El antropólogo, por lo regular, se mueve con las variables opuestas, y piensa en comunicar su trabajo sobre todo a sus colegas especialistas. (Alsina y Gaya, 2001).

Estas reflexiones, según la panorámica de cómo los periodistas construyen otras culturas, propician los primeros cuestionamientos para descubrir al periodista "haciendo $0^{10 "}$ cultura. Algunos suponen que $s u$ cultura es la cultura. Al informar sobre cualquier asunto, se toman dos perspectivas sobre la propia identidad y la de los otros: una sentimental (los valores) y otra mental (racional), pero en ese proceso "el diferente se nos muestra como

10 Este "haciendo" ha de entenderse no sólo como enriquecimiento, sino como modificación o efecto que altera la cultura en proporciones imperceptibles o a gran escala (N. del A.). 
un ser deficiente", según el análisis de Miguel Rodrigo Alsina y de Catalina Gaya Morla (2001), profesores de la Universidad Autónoma de Barcelona.

Sin plena conciencia, se asume "lo étnico" como una expresión que debe asignarse a otros grupos humanos, porque se cree que el grupo propio es "el normal", el que establece "la norma de todas las cosas" (Alsina y Gaya, 2001). El etnocentrismo periodístico es más notorio en el registro de hechos políticos o deportivos, sobre todo cuando se destacan las diferencias culturales de unas naciones frente a otras y, en mayor proporción, cuando se descubren características universales de los pueblos. (Alsina y Gaya, 2001).

Al aludir por ejemplo a la participación en unos Juegos Olímpicos, son usuales expresiones como las siguientes: "España ganó dos medallas"; "Cuba barrió en boxeo"; "Con Laos brilla el oro", cuando es muy claro que los países por sí mismo no ganan ni dejan de ganar en este tipo de competencias, según advierten Alsina y Gaya (2011).

Los estereotipos son otros recursos a los que acuden algunos periodistas cuando informan a su audiencia sobre temas internacionales ${ }^{11}$. La calificación generalizada de "ilegales", la asociación de conflictos con algunas minorías étnicas; la mención de religión, raza ${ }^{\mathbf{1 2}}$, origen, entre otros, constituyen algunos de esos recursos aplicados en la prensa, sin que exista justificación alguna (2001, p. 109).

La interculturalidad debe referirse a las relaciones con otras culturas, no a la instalación de las apreciaciones de éstas a partir de la propia identidad, concluyen Alsina y Gaya (2001). Ese resbaladizo concepto de cultura obliga a demarcar hasta dónde se mueve su efecto. De acuerdo con las circunstancias, entonces, éste sería geográfico, temporal, grupal o dependería de sus propósitos últimos, donde la cultura sería sólo un pretexto.

En estos tiempos, la experiencia estética en un mundo industrializado ha llevado también a considerar la economía de la cultura y las industrias culturales para su estudio. Otro investigador, Elkin Rubiano Pinilla (2006), acerca esta visión de cultura tomando la definición misma de tal término, pero apoyado en las nociones de estética, economía y política, y esta última desprendida de la intervención administrativa gubernamental.

11 El Colegio de Periodistas de Cataluña, según refieren Alsina y Gaya, publicó un manual con la intención de superar esas tendencias xenófobas en el tratamiento periodístico. (Comissió Mitjans i Xenofobia, 1998).

12 Alsina y Gaya toman como modelo la pregunta que sugiere el lingüista holandés Teun Van Dijk: "¿Mencionaría usted la raza si la persona fuera blanca?". (Van Dijk, 1991). 
Rubiano Pinilla expone las acciones de las entidades estatales que deben velar por la promoción, apoyo y divulgación de la cultura en Bogotá: el Instituto Distrital de Cultura y Turismo y el Consejo Local de Cultura de la localidad de La Candelaria; y cuáles son los elementos que median entre el discurso y la acción de éstas. (Rubiano, 2006).

Las políticas culturales no se pueden aplicar adecuadamente sin antes haber descubierto las experiencias simbólicas de los ciudadanos; ello implica una remisión a la experiencia estética y, luego, al consumo cultural. (Rubiano, 2006). Es urgente, dice Rubiano Pinilla, que las facultades de comunicación y de periodismo, o de campos semejantes, en sus contenidos extiendan disciplinas que apenas se mencionan en las clases regulares. Es necesario involucrar perspectivas diversas, porque todas ellas intervienen en el hacer de la cultura.

[...] Un problema extendido en las facultades de ciencias sociales cuando separan, por ejemplo, teoría y método: el primero convertido en la enumeración abstracta de conceptos y el segundo en un paseo ritual por herramientas sin referencia epistemológica... la teoría se presenta como compartimento separado: por un lado está el consumo cultural, la recepción y las audiencias, y por el otro, la economía política de los medios de comunicación y las industrias culturales. (Rubiano, 2006, p. 107).

No obstante, la misma naturaleza humana, inclinada a la comunicación, ha permitido una organización bajo la forma de "culturas particulares" (Guachetá y Medina, 1992); la relación entre comunicación y cultura se estrecha con el sostenimiento y evolución; cada grupo humano, con tales distinciones, supone que la única visión válida del universo es la suya. Así, cada perspectiva parece ser, para los ojos de cada miembro de una cultura determinada, la única existente; es un concepto de realidad socialmente compartido, porque si un hombre, un ser humano prescinde del asidero de una cultura se convertirá en "un mamífero más". (Guachetá y Medina, 1992).

En ese marco, construido por símbolos y, por supuesto, con significados, aparecen las convenciones para establecer valoraciones. El hombre deja ser gregario de sus impulsos, como cualquier animal que responde sólo a los instintos, porque el hombre es un ser pensante; no obstante, se mantiene en otra manera de sumisión si no es consciente de que la cultura es una construcción humana. (Guachetá y Medina, 1992).

Por tanto, es necesaria la reconstrucción constante de la comunicación, pero de comunicación efectiva, para que cada ser humano sea escuchado abiertamente en el ambiente donde se desenvuelve y se evite cualquier recurso de coacción sobre éste (1992). 
Concretan Guachetá y Medina (1992) cómo, de manera clara, el periodismo todo el tiempo está construyendo, derruyendo o afectando de cualquier manera el dinamismo cultural, porque "si los espacios de la comunicación se cierran, surge el terrorismo como otra forma de expresión".

\section{Una Espiral y una estética}

Partiendo de "un análisis de la teoría literaria" y estableciendo "una crítica heterogénea", la investigadora María José Montoya Durana (2007) tomó los números de la revista Espiral para buscar cómo en ésta se exponía una repartición más amplia de la estética en "pro de la humanización de la historia".

En esa investigación sólo se toma la crítica literaria como un elemento con el cual se busca precisar un objetivo más amplio: el compromiso del hombre y el arte, "que mueve sus esencias". (Montoya, 2007). La revista Espiral, que circuló mensualmente desde 1944 hasta 1975, en el primer número empieza por cuestionar si hay una cultura colombiana: "¿Existe una cultura nacional?, de José Antonio Lizarazo". (Montoya, 2007).

Por supuesto, más adelante Montoya Durana (2007) indaga cómo en el país "la historia cultural se ha construido alrededor de influencias transitorias"13, y por tanto se advierte de nuevo la intención por aclarar cómo y en qué proporción Espiral, en su doble función, periodística y cultural, ha hecho cultura.

Añadamos algún contexto: La televisión en Colombia fue inaugurada en junio de 1954, pero la masificación de este medio de comunicación apenas tomó fuerza a mediados de la década de los 70, cuando Espiral dejaba de circular. Es pertinente, por tanto, decir que la "crítica literaria depende de la prensa". (Montoya, 2007). También, para determinar en qué proporción algunas manifestaciones culturales inciden entre la gente, se aclara que "técnicamente la marginalidad de un hecho textual no puede medirse con certeza desde su popularidad, pues este no es un indicador de impacto de los productos culturales". (2007, p. 19).

Para conocer Espiral, se trabaja a partir "del entramado de sus autores", quienes son los que desempeñan esa función crítica, y de las declaraciones de independencia política: "... sin cerca ni parcelamientos, donde el que quiera y sepa siembre y el que lo desee y crea conveniente recoja". (Montoya, 2007) ${ }^{14}$.

\footnotetext{
13 María José Montoya Durana toma como referencia Indagaciones e Imágenes (1926), del escritor y periodista colombiano Baldomero Sanín Cano, p. 171.

14 La cita fue tomada del primer número de Espiral, abril de 1944, p. 2.
} 
Montoya Durana recuerda el caso de la revista Voces (1917-1920), de Barranquilla: "Esta revista no tiene programa político alguno, ni seguirá determinada ruta partidista". Y aclara en su propia investigación que [Espiral] "es un aporte a la historia cultural colombiana y a la historia de crítica de arte". (Montoya, 2007). En suma, una revista que hace cultura.

En Espiral, se encuentra una "perspectiva abierta a la variabilidad y a la discusión", donde hay dos principios en la crítica (no siempre literaria): 1. Un arte humano colectivo-social y 2. El arte para manifestar lo bello. Se buscaba expresar la "estructura cultural" y más en una época liberal, cuando la masificación confrontó la "cultura vulgar" con la "alta cultura", y estableció la diferencia para los conceptos de civilización y cultura, la primera con "ideas disecadas", y la segunda, con "ideas vivas". (Montoya, 2007).

Luis Vidales y Clemente Airó dirigieron la revista Espiral desde 1944 hasta 1946. Hubo un receso en la edición, que se reanudó en 1948, cuando quedaron a cargo Airó y Jorge Rojas. (Montoya, 2007).

\section{Un sentimiento}

Una de las investigaciones que más impacto ha causado en el mundo de la crítica literaria de América, independientemente de las simpatías o los rechazos que genera, fue la investigación de la argentina Beatriz Sarlo (2004) acerca de la revistas "amorosas" que circularon en Buenos Aires entre 1917 y 1925.

Aunque esas publicaciones en realidad se constituyeron en "literatura de barrio [...] y predominantemente para mujeres y adolescentes y jóvenes de sectores medios y populares", la aceptación y el gusto fueron tantos que, de una forma u otra, los contenidos influyeron en el dinamismo social y en parte de la cultura argentina de aquel entonces. Aun así, Beatriz Sarlo quiso tratarlas como "literatura y no como el soporte material de las ensoñaciones románticas o perversas de sus lectores pretéritos". Ella considera en su análisis que "los textos fueron fantasías sociales" y que la principal razón por la cual se acudía a éstas era su carga erótica; pues se tenía muy claro que tales revistas estaban destinadas a un público no preparado.

Sarlo halló características comunes en estas publicaciones: 1. Se leían más por placer que por aprender en la literatura. 2. Se trataban temas cotidianos. 3. Siempre había una peripecia sentimental. 4. En todas, se manejaban los clisés y se acudía a un lenguaje estándar. 5. Había una "desregionalización": se miraba "un" campo desde la ciudad. 
Era ésta una época en que la radio estaba ganando seguidores, el cine parecía ser la única opción y el teatro proliferaba, pero los altos costos conformaban una razón para disfrutarlo de vez en cuando. Así, el costo de una revista "romántica", producida para vender, representaba el de medio paquete de cigarrillos y eso aseguraba una lectura, no de "la gran literatura", pero al menos sí para cultivar algún tipo de ésta.

Sarlo (2004) parece aludir a una vida rutinaria, triste, sin muchas esperanzas, donde sólo las ficciones que reflejaran una porción de la existencia daban una razón para seguir adelante, y donde el público ignoraba cómo sus propias debilidades se constituían en las razones del mercado:

La literatura es pensada desde su carácter compensatorio de las vicisitudes reales y, en consecuencia, los escritores son los oficiantes de esta práctica amable: proporcionar a sus lectores un cuadro ideal, donde se reparen moderadamente algunos de los sinsabores de la vida diaria. Una expresión tan explícita de esta ideología literaria corrobora la imagen de escritores profesionales de mercado que se esfuerzan por sintonizar las tendencias y sobre todo las fantasías de su público (p. 95).

Quizás uno de los más detallados aspectos que analiza Sarlo en esta clase de revistas se refiere a la fuerza emotiva que provoca en los lectores. No por nada su investigación se titula El Imperio de los Sentimientos. Entre los muchos elementos que Sarlo considera, está el clisé en que se convierte la palabra "literatura", utilizada para algo que no entraña mayor calidad artística. Se corrobora, eso sí, la misma lucha de los últimos seis siglos como factor recurrente entre los libros más afamados: esa lucha entre la moral y el amor.

Desde el punto de vista sociopolítico, se deduce una ideología en estas revistas: "los derechos al sentimiento son oprimidos por las trabas sociales", dice Sarlo, tomando como respaldo las reflexiones de José Ingenieros; pero se sabe que ésta es una literatura de consumo, en vez de otra ficción; y compensa las relaciones reales entre hombres y mujeres, donde la felicidad, como acto subversivo, se integra en una paradoja para trasgredir y aceptar la norma.

No obstante, en las historias de estas revistas, siempre hay una adecuación de los deseos a la legalidad general, la de las leyes y la de la sociedad. Este tipo de literatura "moldea costumbres y crea artificios del amor y su lenguaje".

En muchas de las escenas, Sarlo descubre una técnica recurrente de la narración: la mirada. Quizás sea éste el más sutil, pero también el más efectivo de los modos en que se pretende enviar un mensaje cuando la sociedad lo impide o lo reprime. 
Otra característica de las narraciones se refiere a la facilidad para acceder a su lectura (aparte de los bajos costos, de los préstamos, etc.). Se trata del modo lineal en el tiempo para contar: los hechos, unos detrás de otros. También, es una narración simple; es decir, los sucesos son impulsados por un solo motor ideológico, moral o social.

Con respecto a los personajes de esas historias, poco verosímiles resultan los perfiles de cada uno, como si no existiera la imperfección en ellos o no se notara la intención de resarcir sus defectos. "Si son bellos, son bellísimos; si son generosos, generosísimos; si son ambiciosos, lo son hasta el final. Se presentan [los personajes] en la exasperación de sus cualidades".

En esos espacios escritos e impresos, compartidos con el teatro, el cine y la canción, se descubre que el valor estético no sólo está en el texto, sino en el mismo funcionamiento social, desde donde un lector asocia, interpreta, recuerda y sueña. En esas revistas "románticas", se tipifican los personajes y se usa un molde estilístico.

Así y todo, estas publicaciones inducían al hábito de la lectura y conformaban un corpus cultural y, hoy, "son instrumentos culturales en el sentido amplio", concluye Beatriz Sarlo en El imperio de los sentimientos (2004).

\section{A manera de conclusión}

La unificada esencia informativa de la mayor parte de los medios masivos de comunicación en el mundo, que se alimentan de las agencias noticiosas y que está en manos de los países más poderosos, intenta homogenizar las características de los seres humanos. Y son pocos quienes han descubierto tal fenómeno, soportado más que nada en la propagación e imposición inconsciente de los últimos inventos de la tecnología. (Ramonet, 2002).

La cobertura universal de la información ha diluido la línea divisoria entre las culturas; se hablará de "cultura", y hasta este término desaparecerá, pues no habrá contraste, y será equiparable a "existencia".

La periodista colombiana Marisol Cano Busquets, quien fue directora del Magazín Dominical, complementa tales interpretaciones de manera más simple, pero, al mismo tiempo, de manera más comprometida: "... desde los medios estamos moldeando, gústenos o no esta palabra, la cultura cotidiana de las mayorías. Por todo esto es conveniente que nos hagamos periódicamente nuestros exámenes de conciencia" (1992). 


\section{Referencias bibliográficas}

Alsina, M., y Gaya M. (2001). Medios de comunicación en interculturalidad. En: Cuadernos de Información, No 14. (pp. 105-110). Santiago.

Barbero J., y Rey, G. (1999). La formación del campo de estudios de Comunicación en Colombia. En: Revista de Estudios Sociales, No 4, agosto (pp. 54-70). Bogotá: Facultad de Ciencias Sociales, Universidad de los Andes.

Barcia, P. (1999). Historia de la historiografía argentina. Desde los orígenes hasta 1917. Buenos Aires: Ediciones Pasco.

Cano, M. (1991) Nuestra líneas de fuga. En: Magazín Dominical de EE. Bogotá: 16 de junio (pp. 14-16).

Follari, A. (2000). Estudios sobre posmodernidad y estudios culturales: ¿sinónimos? En: Revista Latina de Comunicación, No 35. La Laguna: Tenerife.

García, C. (1990). Introducción. En: Sociología y cultura, de Pierre Bourdieu. México D. F.: Editorial Grijalbo S. A.

Geertz, C. (2005). La interpretación de las culturas. Barcelona: Gedisa Editorial.

González, C. (1993). Descripción y análisis de revistas culturales colombianas (tesis). Bogotá: Facultad de Comunicación Social. Pontificia Universidad Javeriana.

Guachetá, M., y Medina, P. (1992). Responsabilidad de la comunicación social en la formación cultural del hombre (tesis). Bogotá D. C.: Facultad de Comunicación Social y Periodismo, Universidad de la Sabana.

Guanipa, M. (2010). Periodismo, comunicación y cultura: tres lados de la misma página. Una experiencia de investigación. Caracas: II Congreso Invecom 2009. GT Periodismo: Prácticas sociales y textuales.

Montoya, M. (2007). Espiral, revista mensual de artes y letras: exploración de archivo empolvado (tesis). Bogotá: Universidad de los Andes. Bogotá D. C.

Rama, Á. (1985). La crítica de la cultura en América Latina. Barcelona: Biblioteca Ayacucho. 
Jairo Enrique Valderrama Valderrama

Ramonet, I. (2002). La tiranía de la comunicación. El papel actual de la comunicación. Barcelona: Editorial Debate S. A.

Rodríguez, F. (2006). Periodismo cultural. Madrid: Editorial Síntesis.

Rubiano, E. (2006). La cultura encrucijada: concepciones, representaciones y apropiaciones de una noción escurridiza (tesis). Bogotá: Facultad de Comunicación y Lenguaje. Pontificia Universidad Javeriana.

Said, E. (2006): Humanismo y crítica democrática. La responsabilidad pública de escritores e intelectuales. Caracas: Editorial Random House Mondadori.

Sarlo, B. (2004). El imperio de los sentimientos. Buenos Aires: Grupo Editorial Norma.

Tuñón, A. (1990). El acontecimiento cultural y la construcción de mitos. En: Anàlisi: cuaderns de comunicación i cultura (pp. 27-41). Barcelona.

Van Dijk, T. (1991). Racism and the press. Londres: Routledge. 